\title{
Inserción laboral en actividades por cuenta propia. Migrantes wixaritari y mazahuas en Aguascalientes, México, 1960-2020 ${ }^{1}$
} Labor insertion in self-employed activities. Wixaritari and Mazahua migrants in Aguas-
calientes, Mexico, 1960-2020

\section{Jorge Alberto Rodríguez Herrera \\ Universidad de Guadalajara, México}

\begin{abstract}
RESUMEN Se trata de un estudio de corte cualitativo apoyado en la etnografía, en el que se contrastan dos maneras distintas de poner en circulación los recursos socioculturales que han permitido a indígenas migrantes insertarse en actividades comerciales por cuenta propia a partir de la década de 1960 en el estado de Aguascalientes, México. Se constata que dichas actividades han sido iniciadas, sostenidas y reproducidas por los wixaritari y mazahuas gracias a las relaciones de paisanaje, parentesco, amistad y compadrazgo, basadas en la confianza, los tratos flexibles y el mantenimiento de relaciones con sus comunidades de origen, así como un despliegue diferenciado de sus atributos identitarios.
\end{abstract}

PALABRAS CLAVES Migración indígena; inserción laboral; franquicia social; economías étnicas.

1. Los datos analizados en el presente trabajo se derivan de dos proyectos de investigación financiados por CONACyT-México a través de su programa de becas posdoctorales, convocatorias 2018(1) "El modelo de comercio de artesanías de las familias de migrantes wixaritari en Aguascalientes, México, 1960-2019; y, 2019(2) "La franquicia social en las actividades comerciales de migrantes indígenas: el caso de los mazahuas en Aguascalientes, México, 1970-2020”. 


\begin{abstract}
This is a qualitative study based on ethnography. Two different ways of putting into circulation the sociocultural resources that have allowed indigenous migrants to engage in commercial activities on their own since the 1960s in the state of Aguascalientes, Mexico are contrasted. It is verified that these activities have been initiated, sustained and reproduced by the Wixaritari and Mazahuas thanks to the relations of peasantry, kinship and compadrazgo, (camaraderie) based on trust, flexibility and the maintenance of relationship with their communities of origin, as well as a differentiated use of their identity attributes.
\end{abstract}

KEY WORDS Indigenous migration; labor insertion; social franchising; ethnic economies.

\title{
Introducción
}

El objetivo del presente trabajo es analizar, desde la propuesta conceptual de franquicia social (FS), las actividades comerciales por cuenta propia desarrolladas por migrantes wixaritari y mazahuas a partir de la década de 1960 en el estado de Aguascalientes, contrastando las maneras en que ambos grupos han desplegado los recursos socioculturales en sus emprendimientos. Dicho análisis se inscribe en una línea de investigación sobre las formas de inserción laboral en actividades por cuenta propia de migrantes pertenecientes a minorías étnicas, desarrollada a partir de la década de 1970 en Estados Unidos y ampliada posteriormente en Europa. En esta línea se ha desarrollado un corpus teórico bajo la noción amplia de economías étnicas, que alude a empresas, negocios o actividades comerciales en que los empleadores y trabajadores comparten una misma etnicidad (Güell, Parella y Valenzuela, 2015). Dentro de este campo han surgido una serie de planteamientos teóricos como el de minorías intermediarias (Bonacich, 1973), el enclave étnico (Portes y Manning, 1985), el modelo encajado mixto (Kloosterman, Van Der Leun y Rath, 1999), el modelo europeo (Arjona y Checa, 2006), y la economía étnica trasnacional (Peraza y Mendoza, 2015; Peraza y Valenzuela, 2018). El abordaje empírico ha sido abundante en ambos contextos. En Estados Unidos han sido estudiados casos de emprendedores étnicos de procedencia china, india, judía (Bonacich, 1973), coreana, japonesa, cubana (Portes y Manning, 1985) y mexicana (Peraza y Mendoza, 2015; Peraza y Valenzuela, 2018). En Europa, destacan los estudios de minorías étnicas dedicadas a las actividades por cuenta propia en distintas áreas urbanas de España donde se han abordado casos de colectivos de migrantes de origen dominicano, argentino, marroquí (Beltrán, Oso y Ribas, 2007). 
En contraste, esta problemática ha sido escasamente abordada en México. Destaca el reciente interés de Arias $(2017 ; 2018)$ por estudiar casos de migrantes rurales internos que emprendieron negocios a lo largo de los siglos XX y XXI en diversas ciudades del país, planteando la existencia de un modelo de negocios basado en la FS, noción desarrollada a partir de la economía étnica, ajustándola al contexto mexicano.

Las investigaciones sobre migrantes indígenas insertados en actividades por cuenta propia en las ciudades mexicanas también son escasas. Destacan cuatro estudios que aportan elementos para entender la manera en que grupos de migrantes pertenecientes a tres pueblos indígenas de México se han insertado en ese tipo de actividades. Los trabajos de Flores y Pérez (2017) sobre los vendedores de fruta nahuas originarios de Hidalgo en la Zona Metropolitana de Guadalajara (ZMG) y Flores, Salinas y Alejandre (2017) sobre los muebleros purépechas de Michoacán en la misma zona urbana, se aproximan a los casos de estudio apoyándose en la propuesta conceptual de FS. En el primer caso, los migrantes han desarrollado un modelo de negocios basado en tres recursos: innovación, red social y apropiaciones. El primer recurso tiene que ver con la experiencia previa en la actividad del migrante y la capacidad de innovación para impulsar el negocio de venta de fruta. Las redes sociales permiten la consolidación y expansión del negocio facilitando el acceso a préstamos, capacitación y trasferencia de conocimientos entre paisanos. Las apropiaciones están relacionadas con la movilidad espacial y la negociación en el espacio urbano para conformar y consolidar rutas de trabajo. Gracias a estos tres recursos los nahuas han creado una red comunitaria que se extiende entre su lugar de origen y la zona urbana donde han consolidado su actividad de venta de fruta. En el segundo caso los autores constatan la existencia de tres elementos que forman parte del modelo de negocios de FS en la actividad de fabricación y venta de muebles de madera de los purépechas asentados en la ZMG: 1) los recursos económicos y sociales se sustentan en relaciones familiares y a partir de la comunidad de origen; 2) el manejo del negocio se aprende y reproduce entre miembros de la misma comunidad; 3 ) los trabajadores se reclutan en función de relaciones de paisanaje, parentesco, amistad y compadrazgo ancladas en los lugares de origen (Flores et al., 2017).

Otro caso es el de migrantes purépechas dedicados a la venta en tianguis en la ZMG abordado por Bayona (2007), quien parte de considerar una inserción laboral restringida para los migrantes indígenas que suelen ocupar trabajos informales, poco duraderos y mal pagados, lo que les impide ascender en la escala social. La alternativa para la mayoría de los migrantes purépechas ha sido dedicarse a las actividades comerciales por cuenta propia. Para lograr esa inserción los migrantes se apoyan en "una compacta red de parientes y paisanos que les ha permitido conseguir y conservar un nicho laboral exitoso desde las primeras generaciones de migrantes, y que permite el ingreso a nuevos migrantes" (Bayona, 2017, p. 128). Las redes de parentesco 
y paisanaje les proporcionan el acceso a mercancías, información sobre tianguis, así como el acceso a préstamos en efectivo para incursionar en la actividad.

Finalmente, González (2017) analiza los circuitos de comercio impulsados por los indígenas mazahuas de San Felipe del Progreso, Estado de México apoyándose en la teoría del actor red de Bruno Latour. En su estudio plantea la existencia de una "red social del paisanaje”. La actividad comercial mazahua se sustenta en esa forma social primaria definida por González como el paisanaje, es decir, "el ser vecino de la comunidad, el ser vecino de una localidad vecina, el ser pariente, el hablar la lengua mazahua, el conocer amigos en común, etcétera." (González, 2017, p. 201). El paisanaje ha permitido a los mazahuas configurar una malla social primaria y multiterritorial que se origina en el comercio, dando forma a un circuito de grandes dimensiones geográficas donde los comercios fijos instalados en varias ciudades importantes del país por migrantes mazahuas permiten reproducir el comercio ambulante desarrollado por otros migrantes mazahuas que llegan a establecerse a esas ciudades.

Desde distintas perspectivas estos estudios coinciden en la importancia de los recursos socioculturales como un elemento crucial en los emprendimientos de los migrantes indígenas. Si bien aportan elementos relevantes sobre las formas en que los migrantes indígenas ponen en circulación dichos recursos, dada la existencia de 68 pueblos indígenas en México, el incremento de los flujos migratorios internos, así como la expansión de actividades por cuenta propia entre migrantes de diversas etnias, todavía hace falta ampliar el conocimiento y explicar de qué maneras emprenden y organizan sus actividades comerciales de acuerdo al pueblo de pertenencia; cuáles son los mecanismos mediante los que despliegan los recursos socioculturales para su inserción laboral en las ciudades; cómo se articulan las redes de parentesco, compadrazgo y amistad que permiten sostener sus actividades por cuenta propia; y, cómo despliegan los migrantes los atributos identitarios para fortalecer sus emprendimientos.

Para analizar la inserción laboral por cuenta propia de migrantes wixaritari y mazahuas, se decidió apoyarse en la propuesta conceptual de FS, ajustando y clarificando los alcances conceptuales que se detallan a continuación.

\section{Franquicia social}

Definida como "un modelo de negocios que se basa en la maximización de recursos socioculturales ante la ausencia de recursos monetarios" (Arias, 2017, p. 7), la noción de FS fue desarrollada por Arias para explicar los emprendimientos de migrantes rurales internos partiendo de la economía étnica, perspectiva teórica que surge en la década de 1970 como una alternativa a los estudios históricos y sociológicos que privilegiaban un acercamiento asimilacionista sobre los inmigrantes en Estados Unidos. Desde esta perspectiva, se consideraba que los migrantes formaban parte de minorías 
destinadas a ocupar empleos poco calificados y mal remunerados (Herranz, 2007). En contraste, desde una perspectiva neomarxista, se comenzó a desarrollar un corpus teórico que constataba la existencia de varias formas de inserción laboral, diversas vías de movilidad social y distintos procesos de asimilación, destacando algunas formas de inserción autónoma y empresarial de grupos étnicos de inmigrantes como una vía para ascender socialmente (Portes y Manning, 1985). Después de décadas la teoría se ha ampliado y ajustado al contexto europeo incorporando diversos elementos como son las especificidades de las minorías étnicas, los factores culturales y estructurales entre otros (Güell et al., 2015).

La noción de FS se desarrolló tomando como punto de partida la definición de Beltrán y Sáiz (2013) sobre economía étnica, entendida como el estudio de actividades económicas con un considerable índice de propiedad y control de las mismas por parte de grupos minoritarios cuyo origen se encuentra en procesos migratorios, adoptando, además, tres conjuntos de factores que potencian y definen la actividad empresarial: estructurales, individuales y socioculturales (Arias, 2017).

Los factores estructurales son abordados por Arias en sintonía con el modelo de imbricación mixta propuesto por Kloosterman et al. (1999) que tratan de articular lo estructural y lo cultural. Desde esta perspectiva la tendencia al emprendimiento étnico se explica considerando las peculiaridades del grupo étnico y la estructura de oportunidades en la sociedad de destino. Arias aborda, además, los factores económicos y las características culturales de los lugares de origen, “...lo que permite captar los procesos locales que enmarcaron las salidas y posibilitaron una inserción laboral peculiar en las ciudades." (Arias, 2017, p. 13).

Las características individuales de los migrantes internos son abordadas en la propuesta de FS considerando los elementos culturales que motivaron a los migrantes internos a descubrir y aprovechar los nichos que surgieron en distintas ciudades para desarrollar giros novedosos que resultaron viables, dinámicos y prósperos. En esa línea, Portes y Zhou (1996) han mencionado la importancia de algunos migrantes que asumen un liderazgo, volviéndose empleadores de otros migrantes coétnicos.

En cuanto a los factores socioculturales, en la literatura sobre economías étnicas se coincide en la dependencia de los emprendimientos al capital social proporcionado por los recursos étnicos, que incluyen:

“...el valor de la lealtad y la confianza, los lazos de solidaridad y reciprocidad, el empleo de coétnicos, la ayuda familiar, las facilidades de préstamo de dinero por parte de familiares, amigos y vecinos, la socialización étnica y lingüística en determinados valores y actitudes, así como el peso que juegan las tradiciones y estrategias económicas a menudo vinculadas a los lugares de origen."(Beltrán et al., 2007, p. 27). 
A partir de la importancia que tienen los recursos socioculturales en los emprendimientos de los migrantes rurales, Arias delimita cinco condiciones que reúne el modelo de negocios basado en la FS: 1) el arranque de los negocios es a través de relaciones personales de confianza basadas en las comunidades de origen; 2) los establecimientos son de un mismo giro, fueron iniciados y permanecen en poder de vecinos de la misma localidad de origen; 3 ) el manejo de los negocios se aprende y reproduce entre paisanos; 4) la dedicación de los empresarios a los negocios es una forma de autoexplotación; 5) los trabajadores se reclutan con base en relaciones de paisanaje, parentesco, amistad y compadrazgo anclados en los lugares de origen (Arias, 2017, p. 7). Esas condiciones se sostienen en la transversalización de tres principios: "confian$\mathrm{za}$, flexibilidad y mantenimiento de relaciones y redes de relaciones sociales entre las comunidades de origen y las poblaciones de destino" (Arias, 2017, p. 23).

Ahora bien, en los abordajes sobre las economías étnicas se ha privilegiado el estudio de grupos de inmigrantes internacionales en los que empleadores y empleados comparten una misma etnicidad, emprendiendo negocios exitosos. La propuesta conceptual de FS ha sido ajustada al contexto mexicano, ampliándose en tres sentidos: 1) se incluye a migrantes que no pertenecen a una minoría étnica; 2) los emprendedores participan en flujos migratorios internos; 3) abarca tanto migrantes exitosos, es decir, hombres o mujeres de negocios ampliamente reconocidos en sus nichos de actividad, como migrantes que desarrollan negocios o actividades comerciales de dimensiones modestas.

Además de esas adecuaciones, para abordar la incorporación en actividades por cuenta propia de migrantes wixaritari y mazahuas es necesario ampliar la propuesta de FS, así como clarificar alcances conceptuales considerando los siguientes elementos:

Primero: El concepto de inserción laboral por cuenta propia utilizado en este trabajo es central en la teoría de las economías étnicas, alude a una manera autónoma en que los inmigrantes se incluyen en la nueva economía. Si bien este es un factor importante, no es el único que explica la integración social de los migrantes en las sociedades de destino (Herranz, 2007).

Segundo: Como ya se señaló, la propuesta de FS se amplía a migrantes que no forman parte de una minoría étnica. En contraste, los indígenas de México han enfrentado un proceso de etnización que los ha colocado como minoría estigmatizada y marginalizada (Oehmichen, 2015). Por otro lado, desde la economía étnica se ha puesto atención en minorías étnicas de inmigrantes internacionales. En cambio, los migrantes indígenas enfrentan los procesos de etnización en su propio territorio, es decir, pertenecen a un pueblo indígena pero también son mexicanos. La propuesta de Beltrán et al. (2007) sobre el elemento de la etnicidad encaja con esa condición. Estos autores han señalado la necesidad de una definición amplia de empresariado étnico 
que no solamente considere a las minorías étnicas de inmigrantes internacionales si no que abarque a grupos étnicos de origen migrante o no, poniendo como ejemplo al pueblo gitano que se dedica a la venta ambulante en España y que ha combinado sus "peculiaridades étnicas con actividades empresariales" (Beltrán et al., 2007, p. 25).

Tercero: El principio de mantenimiento de redes de relaciones sociales entre las comunidades de origen y lugares de destino de los migrantes en la propuesta de FS, solamente considera dos puntos geográficos donde se articulan las relaciones. La intensa movilidad geográfica de los migrantes indígenas entre sus comunidades de origen y una extensa red de lugares donde desarrollan sus actividades comerciales ha dado lugar a una configuración espacial más amplia en términos geográficos. Se requieren, conceptualizaciones caracterizadas por una mayor porosidad, fluidez y extensibilidad (Güell et al., 2015) que capten “...los procesos a través de los cuales los migrantes forjan y mantienen múltiples relaciones sociales entrelazadas, uniendo a las sociedades de origen y las sociedades de destino." (Arjona y Checa, 2006, p.132). El concepto de comunidad extendida resulta adecuado para abordar la intensa movilidad geográfica de los migrantes indígenas. Dicho concepto refiere a “...comunidades que se ubican en más de un espacio y región y que, sin embargo, suelen gravitar en torno a un territorio ancestral o de origen" (Oehmichen, 2015, p. 30).

Cuarto: Light (2007) considera que en las economías de propiedad étnica no existe explotación ya que la mayoría de los trabajadores son propietarios o miembros de la familia no asalariados. En muchos casos el trabajo de esposas e hijos sin salario a cambio constituye una condición necesaria para la supervivencia del negocio o empresa. Desde la propuesta de FS se plantea otra perspectiva considerando como autoexplotación ese enorme esfuerzo por parte de los migrantes empresarios y sus familiares para poner en marcha y operar los negocios (Arias, 2017). En ese sentido el término de autoexplotación no está relacionado con un diferencial entre ganancia y salario, sino con someterse a largas jornadas de trabajo, desarrollar las actividades comerciales en condiciones difíciles y hacer sacrificios para ahorrar recursos.

Quinto: Finalmente cabe aclarar que las economías étnicas pueden desarrollarse en tres subsectores: formal, informal e ilegal (Tienda y Raijman, 2000). En el caso de las actividades comerciales de migrantes indígenas, son pocos los casos en que se desarrollan negocios en el sector formal de la economía, es decir, están registrados oficialmente y pagan impuestos. En general los indígenas migrantes se desempeñan en el subsector informal, producen y comercializan mercancías legales, pero no pagan impuestos, ni tienen reconocimiento oficial. Algunos indígenas también se han involucrado en el subsector ilegal, manufacturan y distribuyen productos o mercancías prohibidas como videos y discos apócrifos. Para los migrantes desempeñarse en estos subsectores implica una lucha constante con las autoridades que regulan el comercio, quedando expuestos a la confiscación de mercancías, multas administrativas o sanciones más severas como el encarcelamiento. 


\section{Estrategia metodológica}

Los datos analizados se derivan de un estudio cualitativo apoyado en la etnografía, desarrollado entre 2018 y 2020. El primer año se abordó el caso de migrantes wixaritari originarios de la región del Gran Nayar en la Sierra Madre Occidental dedicados al giro del arte y artesanía de chaquira. Se realizó trabajo de campo entre los meses de agosto a diciembre de 2018 y los hallazgos de investigación fueron publicados como avances. Un segundo año se dedicó al caso de migrantes mazahuas originarios del Estado de México, dedicados a una diversidad de giros comerciales. El trabajo de campo en este caso se realizó entre septiembre de 2019 y enero de 2020 y los hallazgos también fueron publicados como avances. El abordaje de ambos casos permitió contar con elementos para contrastar las maneras en que migrantes wixaritari y mazahuas han puesto en circulación los recursos socioculturales que les han permitido emprender negocios y actividades comerciales. Ese análisis comparativo es el que se expone en el presente trabajo.

A lo largo de la investigación se realizaron registros en diarios de campo. Se hicieron recorridos por los puntos donde wixaritari y mazahuas desarrollan sus actividades comerciales y se visitaron sus viviendas con el fin de observar los procesos de manufactura de artesanías, así como las maneras en que organizan sus actividades entre los miembros de la familia. En total se realizaron entrevistas a profundidad a 36 migrantes, 24 wixaritari de los cuales 14 fueron mujeres y 10 varones; y, 12 mazahuas de ellos 8 fueron varones y 4 mujeres. En el caso de los wixaritari las edades de los entrevistados oscilaron entre los 18 y 58 años de edad, representando a dos generaciones de migrantes: los pioneros llegados en la década de 1960 a la ciudad de Aguascalientes y los hijos de migrantes que han nacido en el estado. De los mazahuas cuatro entrevistados fueron migrantes de primera generación llegados a Aguascalientes entre finales de la década de 1970 y finales de la siguiente con edades de entre 51 y 71 años. Los demás migrantes fueron de segunda generación con edades de los 22 a los 47 años. Con cada migrante se llevó a cabo más de una sesión de entrevista, tanto en sus viviendas o albergues como en sus espacios de trabajo. Se utilizó el enfoque de los relatos de vida temáticos (life stories), lo que permitió profundizar en aspectos específicos de las trayectorias de vida de los migrantes como la trayectoria migratoria y laboral, así como las relaciones con otros paisanos y comunidades de origen que han permitido desarrollar las actividades comerciales. La mayor parte de las entrevistas fueron grabadas y transcritas y en el caso de los wixaritari se contó con el apoyo de un migrante como interprete debido a que varios de los entrevistados, sobre todo las mujeres, dominan poco el español.

Como es sabido, los grupos de migrantes son poblaciones difícilmente accesibles por la intensa movilidad geográfica, la dispersión de los lugares donde se asientan en las ciudades, así como por su renuencia a participar en investigaciones. La técnica de 
muestreo no probabilístico de bola de nieve, que se utiliza en investigaciones cualitativas con grupos caracterizados como difícilmente accesibles (Atkinson y Flint, 2001), permitió solventar esta dificultad. A partir de un acercamiento constante y prolongado se logró ganar la confianza de migrantes wixaritari y mazahuas en Aguascalientes. De esa manera, el primer migrante facilitó el contacto con otro, quien a su vez ayudó a contactar a otro y así sucesivamente.

Adicionalmente, se aplicó una microencuesta a los jefes/jefas de familia con el fin de captar información sobre la composición de los hogares, incluyendo un cuestionario sobre la experiencia migratoria de cada integrante. En total se registró información sobre 7 familias extendidas con 47 miembros wixaritari que se asientan en viviendas arrendadas o prestadas y 5 familias con 26 miembros del mismo grupo que han permanecido por periodos prolongados de tiempo en un albergue de la capital. De las familias mazahuas se registró información sobre 8 familias con 34 miembros integrantes.

También se realizaron entrevistas a personal del Centro de Desarrollo Indígena de Aguascalientes, a representantes del albergue Casa MAIS y a ex integrantes de la Asociación Laicos del Nayar. Se accedió a los registros sobre migrantes indígenas del Centro y MAIS de los cuales se procesó información estadística que fue complementada con información del Atlas de los Pueblos Indígenas de México, lo que permitió dimensionar y caracterizar los flujos migratorios.

\section{Wixaritari y mazahuas}

Los wixaritari (wixárika en singular), nombre con el que se auto identifican los indígenas pertenecientes a la etnia que generalmente se conoce como huichol (Gutiérrez, 2002), comparten territorio con coras, mexicaneros y tepehuanes en la región conocida como el Gran Nayar, localizada en la porción meridional de la Sierra Madre Occidental de México (Figura1). Su territorio de asentamiento tradicional está organizado en cinco gobernanzas (San Andrés Cohamiata, Guadalupe Ocotán, San Sebastián Teponahuaxtlán, Tuxpan de Bolaños y Santa Catarina Cuexcomatitlán), abarcando porciones de cuatro estados del país: Jalisco, Nayarit, Durango y Zacatecas (Neurath, 2003). También existen asentamientos de wixaritari fuera del territorio tradicional como en Tepic, Nayarit, en municipios costeros de ese mismo estado como Acaponeta, Rosamorada, Ruiz, Tuxpan y Santiago Ixcuintla (Gutiérrez, 2002), así como en municipios cercanos a su territorio como Colotlán, Jalisco (Becerra, 2016). Por otro lado, su territorio mítico es más extenso e incluye cinco lugares sagrados, cuatro de ellos localizados fuera de sus gobernanzas en los estados de San Luis Potosí (Wirikuta), Jalisco (Xapawiyen), Durango (Huaxa Manaka) y Nayarit (Tatei Haramara) (De la Peña, 2006). Los últimos datos censales para 2015 contenidos en el Atlas reportan un total de 71, 450 wixaritari en México. El 71\% de su población se concentra en 
ocho municipios de los cuatro estados donde se asientan sus cinco gobernanzas. Sin embargo, varios estudios (Contreras, 2016; Durin y Aguilar, 2008; García de Wiegand, 2016) han dado cuenta de su presencia en una diversidad de destinos turísticos y grandes zonas metropolitanas donde comercian sus artesanías; extensas plantaciones agrícolas donde se dedican al jornalerismo; zonas metropolitanas donde algunos jóvenes se han incorporado a estudios universitarios; y, desde la década de 1980, en Estados Unidos. Los datos del Atlas de los Pueblos Indígenas de México constatan la intensa movilidad geográfica de los wixaritari, ubicando para 2015 su presencia en 253 municipios de 31 estados del país y 3 delegaciones de la Ciudad de México (Comisión Nacional para el Desarrollo de los Pueblos Indígenas (CDI), 2020).

Por su parte algunos mazahuas se auto reconocen como jñatrjo o ñatjo dependiendo de su microrregión de origen (CDI, 2020), sin embargo la mayoría de los migrantes de este pueblo indígena en Aguascalientes se identifican como mazahuas y, en algunos casos, ocultan su identidad indígena como estrategia para evitar actos discriminatorios de la población mestiza. Su territorio tradicional se extiende por 11 municipios en el noroeste del Estado de México y el municipio de Zitácuaro en Michoacán (Figura1). El número de mazahuas para el año 2015 ascendió a 360, 231, siendo uno de los pueblos indígenas con mayor cantidad de población del país. La mayor concentración de población mazahua se registró en 105 municipios del Estado de México donde alcanzó el 87\% del total, observándose que los municipios de San Felipe del Progreso, Temascalcingo e Ixtlahuaca en su territorio tradicional son los más importantes en cuanto al número de población mazahua. Al igual que los wixaritari, la movilidad geográfica es fundamental en los estilos de vida mazahuas (González, 2017) los datos poblacionales para 2015 del Atlas de los Pueblos Indígenas lo confirman, ubicándolos en 502 municipios de 31 estados del país y 16 delegaciones de la Ciudad de México (CDI, 2020).

Pese a que en una buena parte de la literatura sobre estos pueblos se insiste que las actividades agropecuarias son el eje del sustento y la reproducción familiar, se ha documentado que siempre han recurrido a la multiactividad, incluso en el siglo XVII los wixaritari eran reconocidos por ser comerciantes más que identificados como agricultores, dedicándose al comercio de sal que extraían en la costa del Pacífico para proveerla a las minas de Bolaños (Durin, 2003). Sobre los mazahuas se tiene conocimiento que antes de convertirse en campesinos, tras el reparto agrario en su región entre las décadas de 1930 y 1940 , pocos eran agricultores y sus economías familiares se apoyaban en tres actividades: el trabajo asalariado en las haciendas o minas de la región; el comercio a pequeña escala de productos agropecuarios y recolectados en los montes; y, la agricultura de subsistencia practicada en pequeños terrenos (Arizpe, 1978). Lo anterior no quiere decir que la agricultura carezca de importancia para ambos pueblos, por el contrario en ambos casos está ligada a la vida ceremonial. Por 
ello, las familias de ambos pueblos destinan una considerable cantidad de recursos obtenidos de las actividades comerciales a la organización de ceremonias agrícolas en sus comunidades de origen.

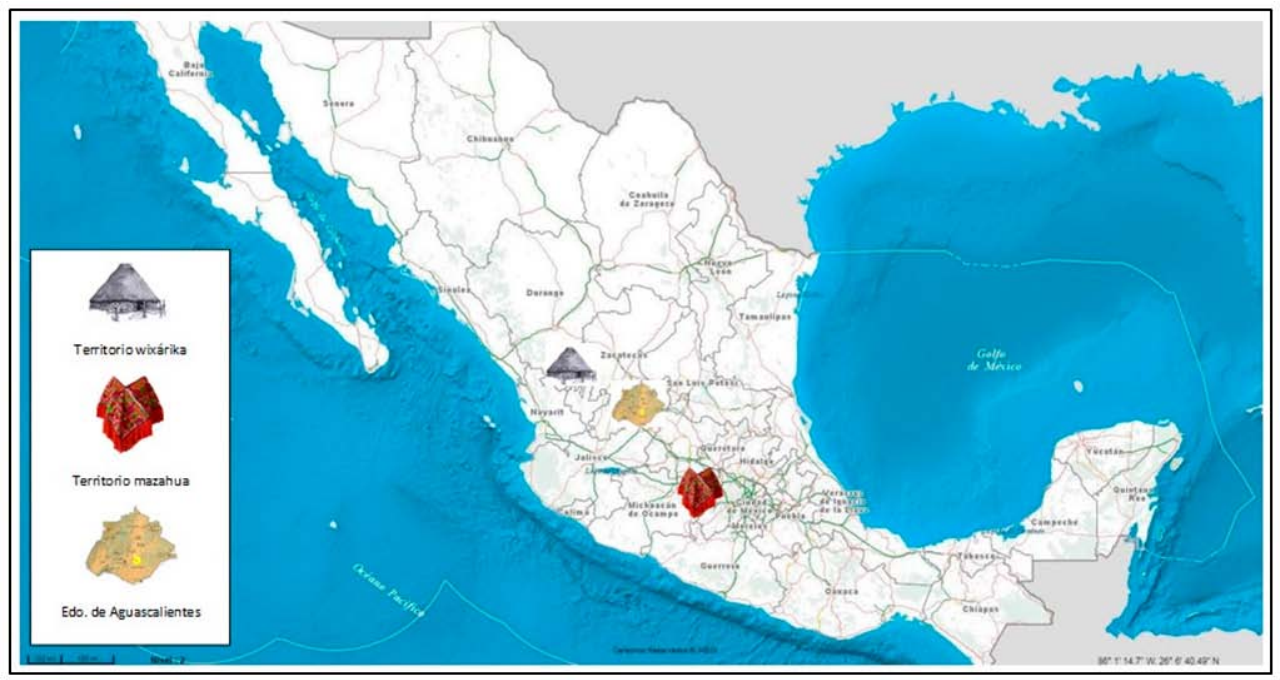

Figura1: Territorios de origen y destino de los migrantes en Aguascalientes. Fuente: elaboración propia con base en el Mapa Digital de México V.6.3.0 del INEGI.

Un rasgo compartido por los individuos de ambos pueblos es la práctica de la migración ligada a las actividades comerciales. Los wixaritari se han desplazado fuera de su territorio para comerciar desde tiempos remotos. Apoyándose en hallazgos arqueológicos, Wiegand sostiene la tesis de que "los viajes de los huicholes a conseguir peyote [en San Luis Potosí] son remanentes de una antigua ruta comercial transdesértica y precolonial" (Wiegand, 2004, p. 53). Sobre los mazahuas no existen referencias sobre estas prácticas hasta finales del siglo XIX, en las descripciones de Rivera Cambas (1883) citadas por Arizpe (1978) que dan cuenta de los indígenas arrieros que llevaban una diversidad de productos silvestres hasta los mercados de Toluca y la Ciudad de México. Por otro lado, en los relatos de ancianos recolectados en la década de 1970, la misma autora encontró que desde generaciones atrás el comercio en pequeña escala era una actividad entre la mayoría de las familias mazahuas. Lo importante es resaltar que en ambos pueblos los indígenas cuentan con una experiencia en desplazamientos geográficos ligados al comercio transmitida por generaciones. 


\section{Migración indígena y actividades comerciales por cuenta propia}

La migración asociada al comercio es una práctica antigua entre distintos pueblos indígenas de México. En el caso de los wixaritari lo constatan los hallazgos ya citados de Wiegand (2004) sobre la ruta comercial precolombina y los de Florentine y Romandía (2009) que a partir de la etnohistoria rastrearon la movilidad geográfica de los wixaritari ligada al comercio, el jornalerismo y las peregrinaciones rituales desde hace más de quinientos años. Sobre otros pueblos indígenas Rubio et al. (2000) han reportado la existencia de datos sobre el origen y destino de las migraciones desde el siglo XIX. Sin embargo, en la literatura antropológica se coincide que las investigaciones sobre migración indígena comienzan a abordarse de manera sistemática en la década de 1970, destacando las aproximaciones histórico-estructurales de Arizpe $(1975 ; 1978)$ sobre indígenas mazahuas, otomíes y nahuas en la Ciudad de México. Gracias a sus estudios se tiene conocimiento que desde la década de 1930 algunos indígenas migraron a la Ciudad de México debido a conflictos posrevolucionarios. En las siguientes décadas estos pioneros migrantes fueron creando redes que facilitaron la inserción de nuevos migrantes, comúnmente familiares y vecinos de sus pueblos de origen.

A partir de la década de 1940, las migraciones rurales hacia las grandes ciudades como México, Guadalajara y Monterrey estaban vinculadas a los procesos de urbanización e industrialización derivados de la aplicación del modelo de desarrollo por sustitución de importaciones (Cárdenas, 2014). En general los migrantes rurales, entre ellos los indígenas, se incorporaban a trabajos asalariados en condiciones precarias (Arias, 2018). Se trataba de "actividades físicamente agotadoras, mal pagadas, poco prestigiosas y al margen de cualquier sistema de seguridad social" (Oehmichen, 2015, p. 180). Sin embargo, algunos migrantes siguieron otra trayectoria, emprendieron actividades por cuenta propia aprovechando las condiciones estructurales favorables que existían en las grandes ciudades entre las décadas de 1940 y 1960. Arias (2018) encontró una coincidencia entre tres casos históricos de migrantes rurales empresarios cuyos negocios en el giro de los alimentos (tortillerías y paleterías) fueron desarrollados en esas décadas y resultaron exitosos gracias a que el proceso de industrialización atrajo enormes contingentes de población rural a las grandes ciudades donde los migrantes demandaban productos alimenticios en grandes cantidades.

Con dimensiones más modestas, en esas mismas décadas, algunos mazahuas comenzaron a reproducir en la Ciudad de México actividades comerciales en pequeña escala que ya realizaban en sus comunidades de origen como la venta de fruta preparada (Chávez, 2008). Excepcionalmente algunos migrantes lograron emprender negocios de mayores dimensiones. Arizpe documentó el caso de un migrante mazahua que migró a Xochimilco (delegación de la Ciudad de México) donde compró tierras para dedicarse a la siembra y cosecha de verduras. El migrante regresaba periódica- 
mente a su pueblo cerca de la comunidad mazahua de Dotejiare para reclutar hombres jóvenes que le ayudaran a trabajar. Así se estableció "un tráfico laboral constante entre Xochimilco y el pueblo de Dotejiare..." (Arizpe, 1978, p. 75).

Entre las mismas décadas los indígenas chocholtecos originarios de Oaxaca emprendieron y consolidaron negocios en la Ciudad de México apoyándose en las redes de relaciones parentales. En un principio se insertaron en diversos oficios y con el paso del tiempo algunos lograron adquirir sus propios negocios en los giros de farmacias, ferreterías y tiendas de abarrote. En el giro de las farmacias los primeros dueños trasmitieron los conocimientos a otros familiares y paisanos hasta lograr la apertura de alrededor de 50 establecimientos en Ciudad de México (Gissi, 2020).

Hasta la década de 1970 los migrantes indígenas encontraron condiciones estructurales favorables en las grandes ciudades mexicanas lo que les permitió desarrollar actividades prosperas tanto en el subsector formal como en el informal de la economía (Arias, 2018). Nolasco (1987) señala que en la década de 1970 existían grupos indígenas que controlaban el comercio al menudeo en los mercados cerca de sus comunidades, como los nahuas de Guerrero quienes se trasladaban con los productos que acaparaban en su territorio hasta la Ciudad de México para venderlos.

A partir de la década de 1980 se observó un incremento en los flujos migratorios indígenas dando como resultado que alrededor del 11\%, unos 600 mil indígenas, se asentaran en otro lugar distinto al de su origen, de los cuales cerca de 20 mil se dedicaban al comercio (Nolasco, 1987). La adopción y puesta en marcha de un modelo de desarrollo neoliberal a partir de 1985, que implicó el abandono de los productores agrícolas del sector de subsistencia por parte del Estado, detonó con mayor fuerza la migración en las comunidades rurales. A partir de entonces las familias y grupos domésticos dependieron cada vez más de los subsidios y salarios obtenidos fuera de sus comunidades, lo que "los obliga a migrar de manera continua." (Arias, 2009, p. 11). Por otro lado, en esta década las condiciones estructurales cambiaron para los migrantes que emprendieron actividades comerciales en las ciudades. Desde entonces la mayoría de los indígenas que se incorporan a estas actividades lo hacen en el subsector informal de la economía y en las condiciones generalizadas del trabajo: "desplazamientos territoriales, nulas prestaciones, nulos servicios financieros para el retiro y la vejez y nulos servicios de seguridad social" (González, 2017, p. 190).

El periodo que abarca de principios de la década de 1990 hasta la actualidad ha llamado la atención de los investigadores por los cambios en los procesos migratorios indígenas. En primer lugar, se incrementó el volumen de la migración indígena, ampliándose el universo de destinos a 112 ciudades de diverso tamaño por toda la geografía nacional (Rubio et al., 2000). En estados pequeños en los que las cifras de migrantes indígenas se mantuvieron bajas a lo largo del siglo XX, se notó un aumento significativo a partir de esta década. Por poner un ejemplo, en Aguascalientes entre 
1990 y 2015 la población indígena se incrementó más de diez veces (Granados y Quezada, 2018). Los cálculos de Díaz (2009) a partir de los datos de INEGI confirman la tendencia al alza en los flujos migratorios, encontrando que entre 1990 y 2000 la población de hablantes de lenguas indígenas disminuyó en 5 puntos porcentuales en las comunidades rurales y aumentó en 3 puntos en las zonas urbanas, lo que significó que alrededor del $35.8 \%$ (cerca de 4 millones) de la población indígena en México se encontrara radicando en zonas urbanas. Si bien para 2015 el perfil predominante de los migrantes indígenas fue el de varones jóvenes (Granados y Quezada, 2018), se tiene conocimiento de que se incorporaron mujeres y niños a los flujos migratorios, ausentándose de sus comunidades de origen familias completas (Cárdenas, 2014). Las ocupaciones en los lugares de destino también se diversificaron: el jornalerismo agrícola, el trabajo en el sector servicios ligado al turismo, el empleo doméstico, la incorporación al sector industrial, particularmente en la construcción y la inserción laboral en el subsector informal de la economía concentrándose en el comercio al por menor (Granados y Quezada, 2018). Finalmente, a estos cambios hay que agregar la transformación de una migración de carácter temporal ligada a los ciclos agrícolas y festivos en las comunidades de origen a una migración cada vez más espaciada y/o definitiva (Arias, 2009).

\section{Migrantes mazahuas y wixaritari en Aguascalientes}

Localizado en el centro del país, Aguascalientes es el tercer estado de México con menor superficie territorial (Figura 1). Para 2015 INEGI reportó 1, 312,544 habitantes, el $66.8 \%$ concentrados en la capital. A pesar de que desde la década de 1920 los censos oficiales han reportado la presencia de población indígena en Aguascalientes, no se trata de pueblos indígenas originarios del estado, sino de un mosaico multiétnico que se fue conformando a lo largo de décadas hasta llegar en el año 2015 a ser integrado por 8,177 indígenas pertenecientes a 25 pueblos indígenas de México; 798 indígenas sin especificar el pueblo al que pertenecen; y 331 hablantes de otra lengua de América. Los mazahuas constituyen el segundo grupo de migrantes más numeroso en el estado representando el $16 \%$ del total aunque su población es difícil de identificar a simple vista debido a que disimulan su presencia para evitar actos discriminatorios de la población mestiza. Aunque menos numeroso, con el 5.4\% del total (CDI, 2020), el grupo más visible por sus elementos identitarios observables es el wixárika.

Si bien hasta la década de 1970, la Ciudad de México era el principal destino migratorio de los mazahuas, los relatos de los migrantes pioneros radicados en Aguascalientes, dan cuenta de una migración temporal al estado desde la década de 1960. Para los mazahuas dedicados a las ventas itinerantes, la ciudad era un punto de descanso cuando recorrían sus rutas hasta la frontera norte del país. En la ciudad se quedaban un par de días, que eran aprovechados también para vender sus productos por las 
calles de distintas colonias. Los pioneros mazahuas se asentaron en la ciudad entre las décadas de 1970 y 1980. Ellos emprendieron actividades comerciales en condiciones que les permitieron acceder a permisos para realizar sus ventas, adquirir viviendas propias e incorporarse a asociaciones de tianguistas. En esas décadas, narraron los pioneros, "la gente de la ciudad era más amable... nos regalaban ropa... nos dejaban vender afuera de las tiendas" (A.J., entrevista, 3-10-2019). Sin embargo, aquellos que migraron a partir de la década de 1990 encontraron otras condiciones. Las actividades comerciales que podían desplegar eran facilitadas por migrantes pioneros con establecimientos comerciales instalados formalmente pero la mayoría de ellos se iniciaron y mantuvieron en el comercio ambulante, es decir, en el subsector informal de la economía. También la actitud de algunos aguascalentenses hacia los migrantes cambió: "hay gente que nos insulta en los semáforos, a veces los inspectores nos quitan la mercancía y cuando andamos vendiendo algunos nos gritan: ¡lárguense de aquí!" (J.H., entrevista, 24-09-2019). Con todo, los mazahuas consideran que Aguascalientes es un buen lugar para vivir porque: está bien conectado con sus pueblos de origen a una distancia de $384 \mathrm{Km}$ que se recorren aproximadamente en cuatro horas gracias a una red de autopistas; se vive bien porque es más tranquilo que otras partes de México; y, es un buen lugar para el comercio.

Para los wixaritari Aguascalientes es parte de su extenso territorio ancestral, un umbral de paso durante sus peregrinaciones hasta Wirikuta en San Luis Potosí. En sus recorridos realizan ceremonias para dejar ofrendas en lugares sagrados, con el fin de que los ancestrales les permitan continuar su camino. Desde la década de 1960 se convirtió en una plaza comercial donde los varones de una familia originaria de Santa Catarina Cuexcomatitlán comerciaban sus artesanías durante la Feria de San Marcos, celebrada entre los meses de abril y mayo cada año. La migración desde esa década hasta la de 1990 se caracterizó por ser estacional, predominantemente masculina y determinada por el ciclo ritual-agrícola. Entre finales de la década de 1990 y principios de la siguiente, integrantes de la Asociación de Laicos del Nayar apoyaron a los wixaritari para extender sus ventas fuera del periodo ferial, consiguiendo espacios en los atrios de varios templos católicos de la capital. Los wixaritari comenzaron a alargar su estancia en la ciudad hasta por tres meses. Alrededor de mediados de la década del 2000, algunos wixaritari extendieron sus estancias en la ciudad y comenzaron una lucha por espacios de venta en el centro de la ciudad. Después de años de conflicto con las administraciones municipales, en 2012, con el apoyo de varios actores aliados, un grupo de diez wixaritari lograron acceder a un espacio para comercializar sus artesanías en la plaza principal de la ciudad y los integrantes de una familia obtuvieron un permiso para instalarse los fines de semana frente al Instituto Cultural de Aguascalientes, también en el centro de la ciudad. Otra familia logró unirse a la asociación de artesanos en el municipio de Calvillo, pueblo mágico que atrae turismo durante 
todo el año y una familia extensa se asentó desde el 2005 en el pueblo de San José de Gracia, lugar que congrega enormes contingentes de fieles religiosos que llegan a visitar el santuario del Cristo Roto. En el lugar la familia wixaritari consiguió un local en el área comercial de dicho santuario. Fuera de estas familias que han accedido a espacios de venta en puntos céntricos de la capital o destinos turísticos, otros migrantes wixaritari que recién llegan a la ciudad recurren al apoyo de sus paisanos para que les comercialicen sus piezas artesanales, ya que no pueden acceder a permisos para vender en la vía pública.

\section{Inserción laboral en actividades por cuenta propia de mazahuas y wixaritari}

Los migrantes de ambos pueblos se han insertado en la economía desplegando formas de organización que no encajan con la lógica capitalista, aun cuando lo hacen en las condiciones generalizadas del trabajo, es decir, en el subsector informal de la economía, sin acceso a créditos bancarios, sin prestaciones laborales y confrontándose cotidianamente con las autoridades que regulan el comercio.

Los mazahuas han emprendido actividades comerciales orientadas al mercado interno en una diversidad de giros comerciales, destacando la venta de utensilios y productos para las tareas del hogar, la elaboración y venta de artesanía de barro, textil y madera, y, la comercialización de una diversidad de artículos demandados por la clientela dependiendo la temporada (adornos navideños, juguetes, regalos para el día de la madre, adornos para día de muertos, diversos objetos utilizados en las fiestas patrias). Las trayectorias laborales de los migrantes mazahuas entrevistados en Aguascalientes, así como los trabajos de González (2017) y Arizpe (1978) permiten identificar cinco modalidades de comercio reproducidas tanto en sus pueblos de origen como en los lugares de destino: venta itinerante recorriendo varios estados del país; "ranchar", es decir, salir a vender en pueblos cercanos a su lugar de asentamiento temporal o permanente; comercio en tianguis, concentraciones de puestos instalados un día de la semana en algún punto de las colonias o pueblos; venta en establecimientos fijos y puestos semi-fijos; y, venta ambulante en cruceros de vialidades importantes, el exterior de escuelas o caminando por las calles de distintas colonias. La dedicación exclusiva a una sola modalidad de comercio se registra sobre todo en mazahuas que tienen establecimientos fijos, pues por lo regular las familias combinan varias modalidades de comercio.

Por su parte, los wixaritari han sabido explotar sus atributos identitarios captando a un público interesado en el arte ligado al ceremonialismo indígena (Le Mûr, 2015; Neurath, 2009), dedicándose a la elaboración y venta de arte y artesanía como las tablas de estambre y las piezas elaboradas con chaquira donde plasman, aunque con fines meramente comerciales, diversas imágenes rituales asociadas con su religión (Neurath, 2013). Se trata de piezas que abandonan las expresiones artísticas sobrias 
de sus objetos rituales para dar paso a diseños psicodélicos demandados en un principio por un público New Age, expandiéndose posteriormente a una diversidad de consumidores en los mercados local, nacional e internacional (Le Mûr, 2015; Neurath, 2013).

A diferencia de la actividad comercial multimodal de los mazahuas, en general los migrantes wixaritari en Aguascalientes han desarrollado un modelo de comercio caracterizado por la fabricación de piezas artesanales de lunes a viernes en la vivienda rentada o el cuarto del albergue donde viven y la comercialización de sus objetos de viernes a domingo en varios puntos del centro de la ciudad, en las cabeceras municipales de Calvillo y San José de Gracia y, durante la Feria de San Marcos y el Festival de Calaveras celebrado entre finales de octubre y principios de noviembre.

En el centro de la organización de las actividades comerciales de mazahuas y wixaritari está la familia. Como en general se ha constatado en las economías étnicas de propiedad (Light, 2007) las empresas o actividades comerciales involucran el trabajo de los miembros integrantes de la familia, quienes regularmente no se constituyen como trabajadores asalariados, sino que conciben el trabajo sin remuneración como una ayuda necesaria para que el negocio o la actividad comercial prospere.

La autoexplotación está en la base de la gestión de las actividades comerciales de mazahuas y wixaritari, ampliándose a los coétnicos que suelen aceptar bajos salarios en el entendido de que aprenderán la actividad para después emprenderla de manera autónoma (Arias, 2017). Entre los migrantes mazahuas y wixaritari la autoexplotación se materializa desarrollando la actividad comercial en condiciones difíciles. Desde la niñez hasta etapas de edad avanzadas, hombres y mujeres trabajan por igual, cubriendo largas jornadas que se extienden durante toda la semana en horarios de hasta 12 horas en los que se combinan los trabajos productivos y reproductivos, observándose que estos últimos recaen sobre todo en las mujeres. Hay madres de familia mazahuas que cargan a sus bebes durante las ventas en la vía pública y alrededor de los seis años de edad los niños mazahuas comienzan a ofrecer dulces o semillas en los cruceros viales de la ciudad como parte del entrenamiento para en un futuro iniciar sus actividades de manera autónoma. Los niños wixaritari aprenden a temprana edad la elaboración de artesanía, realizando diariamente ese trabajo después de cumplir con sus obligaciones escolares. En los últimos años, dadas las restricciones de las autoridades municipales para que los menores de edad no trabajen en los puntos de venta, las madres wixaritari dejan a sus hijas, por lo regular menores de edad, al cuidado de sus hermanos pequeños.

Como en el caso de los Purépechas muebleros de la ZMG (Flores et al., 2017), los mazahuas y wixaritari consideran que en la adolescencia ya dominan la actividad comercial y pueden iniciar a trabajar con independencia de sus padres, aunque por lo general lo hacen con el acompañamiento de la parentela: 
“...como a los 13 años mi papá tenía cargo en la comunidad y no podía salir para vender en la feria. Yo sola me encargué de la venta ese año...A los 14 años me junté con mi pareja y ya empecé sola con lo de la artesanía" (M.G., wixárika, entrevista, 27-09-2018).

“...desde los 15 años yo agarré un carrito de fruta, pero después haz de cuenta que yo era el que administraba el negocio de mi papá. Yo compraba toda la mercancía y ellos me ayudaban se puede decir." (M.J., mazahua, entrevista, 5-11-2019).

Por otro lado, los miembros de las familias de migrantes realizan una diversidad de sacrificios para ahorrar lo más que se pueda recursos económicos como vivir hacinados alquilando colectivamente viviendas económicas, cuartos de vecindad o alojándose en albergues donde hacen aportaciones económicas bajas, durmiendo en los puestos donde comercializan sus productos o en el camión durante las ventas itinerantes de los mazahuas.

Los migrantes de ambos grupos organizan sus actividades comerciales disponiendo libremente de su tiempo. Cuando son las fiestas de su pueblo los mazahuas hacen pausa en sus actividades comerciales y regresan a sus lugares de origen para participar en la celebración y visitar o encontrarse con parientes y amigos que han migrado a otros destinos. Los wixaritari, sobre todo los varones, viajan constantemente entre las ciudades de destino y sus comunidades de origen. Si tienen algún compromiso ceremonial en la sierra, suelen modificar e incluso dejar de lado sus compromisos con los clientes mestizos. Lo más importante para ellos es su vida ceremonial comunitaria ligada al complejo ciclo ceremonial-agrícola Neixa que "consiste en una concatenación de ceremonias, danzas y ofrendas marcadas por los cambios estacionales y el proceso de siembra-crecimiento-corte del maíz." (Chávez, 2015, p. 66).

En ambos casos se puede constatar que la organización de sus actividades comerciales se basa en un modelo de negocios apoyado en los recursos socioculturales que incluyen las redes de relaciones basadas en el paisanaje, el parentesco, la amistad y compadrazgo, así como formas de organización indígena ancestrales que constituyen un capital cultural, similares a la guetza, principio básico de los pueblos indígenas mixtecos y chocholtecos que "consiste en una norma por medio de la cual se apoyan unos a otros más allá de si viven en asentamientos concentrados o dispersos en la colonia y ciudad." (Gissi, 2020, p. 225) o diversas formas de trabajo comunal o familiar que pueden involucrar o no la reciprocidad y la cooperación voluntaria u obligada parecidos al tequio.

El principio de confianza, que suele otorgar la cercanía social y el conocimiento íntimo al pertenecer a la misma familia, comunidad o etnia (Gissi, 2020), sostiene los tratos laborales en las actividades por cuenta propia. Las relaciones basadas en la confianza se extienden entre los mazahuas a todos los integrantes de este pueblo in- 
dígena, independientemente de su microrregión o comunidad de origen. En ese sentido, Oehmichen (2015) encontró entre los mazahuas de Pueblo Nuevo expresiones inclusivas que ligan la pertenencia étnica con los lazos parentales, aún entre quienes no comparten vínculos sanguíneos directos: "todos somos parientes", "todos estamos emparentados con todos” (Oehmichen, 2015, p. 324). Así, las relaciones de confianza se establecen a partir de lazos primarios más allá del parentesco, tales como la vecindad, la amistad y el ser conocidos (González, 2017), constituyendo lo que González ha definido, en el caso de los mazahuas del municipio de San Felipe del Progreso, como la red social del paisanaje que ha permitido desarrollar a los mazahuas una actividad comercial de grandes proporciones geográficas organizada a partir de establecimientos fijos instalados por migrantes pioneros en varias ciudades importantes que potencian el comercio ambulante practicado por otros coétnicos (González, 2017). Entre los mazahuas de Aguascalientes, la confianza permite potenciar las actividades comerciales con la incorporación de nuevos migrantes quienes son orientados por sus paisanos que desarrollan alguna actividad comercial o pueden acceder a mercancía sin tener que invertir recursos económicos gracias al crédito sin garantías y el préstamo de mercancía brindado por sus paisanos con pequeñas fábricas o negocios establecidos ya sea en sus pueblos de origen o en la ciudad de destino. En los siguientes registros de entrevista se ilustran algunas relaciones basadas en la confianza:

"Todo es de allá, pura gente mazahua. Son barrios o son pueblos donde venden las cosas...Son fábricas donde los hacen...de todo eso que vendemos acá en la ciudad, allá lo hacen. Es pura gente mazahua. Todos dan crédito nomás a los conocidos." (U.F., entrevista, 21-11-2019).

“A mi compadre Ángel lo recibí aquí y lo ayudé a empezar. Llegó con su señora y dos hijos, sin nada. Lo dejé que se quedara a vivir ahí en la vecindad con nosotros. Luego le fie un carrito para que empezara a vender fruta y le dije como hacerle." (P.J., entrevista, 3-10-2019).

Entre los wixaritari las relaciones basadas en la confianza operan con mayor fuerza entre migrantes originarios de la misma cabecera comunal, aunque pueden extenderse a otros coétnicos originarios de distinta cabecera sobre todo tratándose de las segundas generaciones de migrantes:

"Antes casi no nos llevamos entre los que somos de diferente comunidad, pero aquí en la ciudad vienen a mi casa por chaquira todos los que son de allá, no importa de qué cabecera sean. Yo traigo la chaquira de Guadalajara y les doy crédito. También trabajan conmigo unas muchachas que son de Santa Catarina, San Sebastián y otras de San Andrés." (A.C., entrevista, 2211-2018). 
En la base de estas formas de organizar las actividades comerciales están los tratos flexibles, otro de los principios del modelo de negocios basado en la FS. La importancia de este principio radica en que el capital social suple la falta de recursos económicos para iniciar los negocios o actividades comerciales (Arias, 2017). Son tratos en los que la palabra tiene un gran peso, no hay contratos por escrito, ni bienes materiales en garantía de por medio. Se trata de una serie de arreglos flexibles y heterogéneos que se "adecuan a los cambios en las vicisitudes y trayectorias de vida" (Arias, 2017, p. 24) de los migrantes y sus coétnicos que permanecen en las comunidades de origen. Entre los mazahuas y wixaritari de Aguascalientes los tratos flexibles representan una ventaja tanto para los migrantes como para sus coétnicos que tienen talleres artesanales o pequeñas fábricas en sus comunidades de origen, en los lugares de destino o bien trabajan en sus casas a pequeña escala. A los migrantes les permite acceder a mercancías sin tener que desembolsar dinero en efectivo gracias a la existencia de por lo menos cuatro mecanismos documentados durante el trabajo de campo: el crédito con o sin anticipo; el préstamo de mercancía por día sin garantía; la trasferencia de trabajo artesanal a las familias de las comunidades a cambio de un pago; el pago acordado entre el dueño de la mercancía y un vendedor ayudante. Los siguientes registros de entrevista ilustran algunos de esos tratos flexibles:

“...Nosotros le vendíamos las macetas de barro natural a un vecino en el pueblo, ya él las mandaba pintar. Era fiado. Se las dábamos y ya cuando regresaba de vender nos pagaba. Así era el trato. No nos daba todo el dinero junto." (U.F., mazahua, entrevista, 21-11-2019).

"Yo traigo cuadros de estambre, piezas decoradas con chaquira y morrales tejidos en telar de la sierra. Allá hay conocidos que me pasan la mercancía. Cuando me la entregan les pago la mitad y ya cuando la vendo les acabo de pagar." (M.G., wixárika, entrevista, 26-09-2018).

"Cuando me hacen pedidos grandes de tiras de chaquira para adornar zapato en la fábrica, hasta 250 docenas de tiras por semana, con las muchachas que me ayudan aquí en Aguas no alcanzo a tenerlo. Voy a San Andrés para que me ayuden mis familiares y otros conocidos. Son unos cien los que me ayudan. Yo les pago por cada docena de tiras que me hacen." (A.C., wixárika, entrevista, 11-09-2018).

"La primera vez que me invitaron fue para vender macetas de barro en una ruta hasta Veracruz...Para mí, la verdad, los primeros viajes, mientras le agarraba bien el movimiento, acepté que el dueño me pagara por viaje. Me convenía así porque yo no sabía hablar muy bien el español, entonces salía como temeroso, con miedo o pena." (A.J., mazahua, entrevista, 3-10-2019). 
Para los productores este tipo de tratos les permiten poner en circulación sus mercancías sin tener que desplazarse de sus lugares de origen. En el caso de los wixaritari es una ayuda crucial para una persona que tiene el cargo de peyotero pues implica, en algunas cabeceras comunales, la restricción de movilidad migratoria durante los cinco años que dura el cargo (Neurath, 2001), que además es honorario e implica fuertes gastos para organizar una serie de ceremonias.

Finalmente, las redes de relaciones con las comunidades de origen operan de distinta manera entre los migrantes de ambos pueblos. Las relaciones se sostienen en el caso de los mazahuas a partir del sistema de cargos tradicionales, pero, sobre todo, gracias a las alianzas simbólicas como el compadrazgo y el matrimonio entre coétnicos. Este tipo de alianzas suelen formalizarse en el pueblo de origen, por lo que los migrantes regresan para organizar celebraciones que duran varios días y requieren de fuertes gastos. Los migrantes mazahuas, además, han integrado "vecindarios étnicos" en zonas urbanas como la de Monterrey, en estos asentamientos reproducen la organización espacial del pueblo de origen basada en barrios: los originarios de Boshésda viven en La Esperanza, Escobedo; los de Bombaro y Santiago Coachochitlan residen en distintas colonias del sector de la Alianza, Monterrey (Durin y Pernet, 2010). En Aguascalientes se repiten estos patrones que reproducen la vecindad entre migrantes originarios del mismo pueblo: en la colonia Las Cumbres se asientan familias originarias de San Felipe del Progreso, Estado de México; en el fraccionamiento Peralta, las familias procedentes de Santiago Coachochitlan, Temascalcingo; y, en la colonia El Torito, municipio de Jesús María, se asientan varias familias de Mesa de Santiago, Temascalcingo. Lo anterior confirma la tesis sobre existencia de la comunidad extendida, es decir, “...las comunidades mazahuas son comunidades extraterritoriales...se han extendido en el espacio geográfico, han traspasado las fronteras regionales... y se han re-territorializado en una multiplicidad de lugares urbanos de México..." (Oehmichen, 2002, p. 123), al mismo tiempo, gracias a las alianzas simbólicas y cargos tradicionales, estas comunidades asentadas en zonas urbanas, "...suelen gravitar en torno a un territorio ancestral o de origen.” (Oehmichen, 2015, p. 30).

Ese mantenimiento de redes de relaciones, permite que las actividades comerciales o negocios permanezcan en manos de familiares, otros parientes, vecinos de la comunidad o coétnicos (Arias, 2017). Entre los migrantes mazahuas de Aguascalientes los pioneros en el giro de la venta de fruta preparada han abierto la oportunidad en la ciudad para que las nuevas generaciones de migrantes accedan a puntos de venta que cuenta con permisos municipales que fueron otorgados a finales de la década de 1970, así como lugares en distintos tianguis que fueron obtenidos entre la misma década y principios de la siguiente que se han mantenido en manos de mazahuas hasta la actualidad. 
"En 1976 mi esposa consiguió un lugar ahí en el centro para vender la fruta en un carrito... cuando se casó mi muchacha, a mí yerno le di ese puesto porque no tenía donde trabajar. Le dije a mi hija: se van al puesto que tengo en el centro, los demás ya tenían trabajo en los tianguis. Me dijo: bueno, si quieres dámelo o préstamelo, déjame trabajar... (P.J. entrevista, 7-11-2019). Mi papá los orientó y los acomodó a todos, son todos mis tíos de lado de los papás de mi mamá...todos venden lo mismo [fruta] pero en diferentes tianguis... (M.J., entrevista, 5-11-2019).

Los wixaritari, por su parte, han mantenido sus redes de relaciones a partir de la participación en el complejo ciclo ceremonial-agrícola en el que se involucran de manera fundamental los migrantes, lo que implica desplazamientos constantes entre las ciudades de destino y las comunidades de origen. Esto de gran importancia considerando que para los wixaritari el éxito de las actividades comerciales no depende de las leyes del mercado sino del cumplimiento de las obligaciones rituales que implican la organización de ceremonias en las que se realizan ofrendas a los ancestros con el fin de mantenerlos en calma. El ciclo ritual-agrícola comprende anualmente al menos tres ceremonias en las que los padres de familia tienen que estar presentes en su comunidad de origen. Por otro lado, si surgen problemas de salud entre alguno de los miembros de la familia o las ventas van mal, los migrantes tienen que recurrir a un chamán por lo que se desplazan a buscarlo hasta sus comunidades. Una vez que el chamán identifica el origen del malestar, la pareja e incluso todos los miembros de la familia tienen que viajar hasta los lugares sagrados para dejar ofrendas a alguna deidad. Esto puede ocurrir con frecuencia a lo largo del año. También existen una serie de cargos tradicionales y civiles con carácter obligatorio que implican la presencia del migrante en las comunidades o bien, la realización de peregrinaciones hasta sus sitios sagrados para llevar ofrendas a las deidades que ahí tienen su morada. Cumplir con estos deberes permite a los migrantes continuar formando parte de su comunidad de origen ya que aquellos que los incumplen pueden ser multados, castigados con trabajos comunitarios e incluso expulsados de la comunidad si la falta es grave. Dado que el modelo de comercio wixárika se sostiene y reproduce en gran medida gracias el reclutamiento y trabajo de los wixaritari asentados en sus comunidades de origen, para los migrantes es clave mantener sus relaciones.

\section{Despliegue diferenciado de los atributos identitarios}

Los mazahuas despliegan sus atributos identitarios de una manera dual: cuando es necesario evitar actos de discriminación ocultan los elementos observables de su identidad étnica con el fin de confundirse con la población mestiza, pero los utilizan para mostrar su "distinguibilidad étnica en contextos de interacción específicos" (Oehmichen, 2015, p. 397). Por décadas, esta manera de conducirse ha sido una es- 
trategia ante los esfuerzos por asimilar culturalmente a los indígenas por parte del Estado que hicieron mella en los elementos observables de su identidad, más no en elementos más profundos de la cosmovisión mazahua, conservados incluso entre la segunda y tercera generación de migrantes en la Ciudad de México (Oehmichen, 2002). Por otro lado, los migrantes mazahuas se han percatado del potencial de los elementos identitarios observables como recurso para acceder a beneficios en las ciudades de destino. Oehmichen (2015) lo ha documentado entre migrantes mazahuas de la Ciudad de México:

"Los mazahuas han aprendido a hacer uso político de su identidad étnica para obtener permisos para la venta ambulante, crédito para vivienda, o conseguir financiamiento para algún proyecto por parte de instituciones gubernamentales y organismos no gubernamentales...Hablar la lengua mazahua y portar el traje distintivo... significa tener espacios para el comercio, conseguir apoyos económicos para sus proyectos y establecer vínculos con funcionarios gubernamentales a quienes pueden acudir en caso de ser necesario" (Oehmichen, 2015, pp. 305-306).

Entre los mazahuas que se dedican al comercio en Aguascalientes esta estrategia dual se concreta, por un lado, con el uso cotidiano de ropa similar a la de los citadinos, el ocultamiento del idioma mazahua en público e incluso la negación de su procedencia indígena y, por otro lado, con la conciencia sobre el potencial que guardan los atributos identitarios para acceder a ciertos beneficios. Un ejemplo concreto de esto se documentó durante una reunión de mazahuas celebrada el día 2 de diciembre de 2019 con la finalidad de comenzar a luchar por obtener una representación indígena ante el H. Ayuntamiento de Aguascalientes. Al ponerse de acuerdo para entregar una solicitud a las autoridades competentes, un joven migrante sugirió a los asistentes llevarla en grupo procurando usar sus trajes tradicionales para llamar más la atención. Los asistentes más jóvenes manifestaron desconocer por completo el atuendo tradicional, preguntando a los de mayor edad sobre ello. Uno de los migrantes de mayor edad manifestó tener una vaga idea sobre el atuendo masculino, pero refirió que el traje tradicional de las mujeres todavía era utilizado en ciertas ocasiones. Acordaron entonces, averiguar con los más viejos del pueblo sobre el traje tradicional de los varones con el fin de retomar su uso en situaciones específicas relacionadas con su lucha por la representación indígena.

Por su parte, el éxito de las actividades comerciales de los wixaritari reside en gran medida en que han potenciado sus atributos identitarios, aprovechando un nicho de mercado en el que se exaltan las costumbres locales y poniendo en "evidencia lo más interesante, lo más impactante y lo más exótico de su cultura." (Le Mûr, 2015, p. 115). En Aguascalientes cuando realizan sus ventas, los migrantes llevan vistosos trajes bordados a mano, se comunican entre ellos en su idioma cuando atienden a 
los compradores y elaboran piezas artesanales en sus puestos con el fin de generar certidumbre sobre la autenticidad de los objetos. Por otro lado, han entablado luchas mediáticas en las que aparecen en los principales medios de comunicación del estado pugnado, ante las autoridades que reglamentan el comercio ambulante, por la obtención de permisos de venta en el centro de la ciudad y aglutinando en su defensa a diversos actores como integrantes de ONGs, diputados de izquierda, el titular de Derechos Humanos e incluso funcionarios municipales. Estas estrategias mediáticas, en las que los wixaritari utilizan los medios de comunicación para reivindicar objetivos políticos y el reconocimiento de su cultura, han sido desplegadas por los wixaritari en disputas más amplias como en el caso de la defensa del territorio ceremonial de Wirikuta en el estado de San Luis Potosí ante las corporaciones mineras transnacionales que pretendían reiniciar operaciones para la extracción de oro y plata (Le Mûr, 2018). En esta lucha los wixaritari han utilizado elementos de su identidad étnica exhibiendo, ante los medios masivos de comunicación y en eventos públicos, "símbolos, prácticas y discursos sagrados por parte de expertos ceremoniales wixaritari como parte de una estrategia para proteger el territorio de Wirikuta" (Liffman, 2017, p. 564).

\section{Conclusiones}

Se analizaron dos formas distintas de poner en marcha negocios y actividades comerciales basadas en el modelo de negocios de FS, considerando los cambios en las condiciones estructurales que influyeron en la inserción laboral de mazahuas y wixarita$r i$. Hasta la década de 1970, en las grandes ciudades existieron condiciones propicias para que algunos migrantes lograran desarrollar actividades comerciales prosperas. A partir de finales de la década de 1980 las condiciones se modificaron, con la puesta en marcha del modelo de desarrollo neoliberal la mayoría de los migrantes se insertan en la economía en condiciones precarias.

Con todo, la puesta en circulación de los recursos socioculturales ha permitido hacer frente a las condiciones generalizadas del trabajo, así como a las restricciones que intentan imponer las autoridades encargadas de regular el comercio informal en las ciudades. Por otro lado, al desarrollar sus actividades comerciales los mazahuas y wixaritari han conservado su independencia para administrar el tiempo, lo que les permite cumplir los compromisos con sus comunidades de origen. En el fondo su cosmovisión continúa permeando la organización de las actividades comerciales, para los wixaritari lo más importante continúa siendo mantener en calma a sus deidades, realizando ofrendas en agradecimiento por los recursos económicos obtenidos de la actividad comercial. Mientras que para los mazahuas las alianzas simbólicas selladas en sus pueblos de origen, así como su participación en cargos tradicionales han permitido la consolidación de un comercio de grandes dimensiones geográficas 
desarrollado por los migrantes y quienes fabrican una serie de productos en su región de origen.

En fin, si bien los mazahuas y wixaritari se insertan en la economía capitalista, las lógicas con que despliegan sus actividades comerciales son contrastantes. Podrán laborar en las mismas condiciones generalizadas del trabajo: la informalidad, la eventualidad, la irregularidad de ingresos y la ausencia de prestaciones pero obedeciendo a lógicas más profundas ancladas en su cosmovisión y que han persistido incluso entre la segunda y tercera generación de migrantes, renovándose y cobrando fuerza, aun cuando aparentemente han desaparecido debido al ocultamiento de los elementos identitarios observables en el caso de los mazahuas o involucrando en sus luchas simbólicas a diversos actores en el caso de los wixaritari.

\section{Referencias}

Arias, Patricia (2009). Del arraigo a la diáspora. Dilemas de la familia rural. UdeG/ Miguel Ángel Porrúa.

Arias, Patricia (coord.) (2017). Migrantes exitosos. La franquicia social como modelo de negocios. UdeG.

Arias, Patricia (2018). Una historia de migrantes empresarios en México. 19401960. Relaciones Estudios de Historia y Sociedad, 155: 277-308. Doi: https://doi. org/10.24901/rehs.v39i155.387.

Arizpe, Lourdes (1975). Indígenas en la Ciudad de México. El caso de las Marías. COLMEX.

Arizpe, Lourdes (1978). Migración, etnicismo y cambio económico. Un estudio sobre migrantes campesinos en la Ciudad de México. COLMEX.

Arjona, Ángeles y Juan Checa (2006). Economía étnica. Teorías, conceptos y nuevos avances. Revista Internacional de Sociología, 54(45): 117-143.

Atkinson, Rowland y John Flint (2001). Accessing Hidden and Hard-to-Reach Populations: Snowball Research Strategies. Social Research Update, 33, 1-5.

Bayona-Escat, Eugenia (2007). Comerciantes purépechas en la Zona Metropolitana de Guadalajara. En P. Arias y O. Woo Morales (coord.), ¿Campo o ciudad? Nuevos espacios y formas de vida (pp. 125-148). México: UdeG.

Becerra, José (2016). Procesos interculturales de los wixaritari en Colotlán. (Tesis de doctorado). UdeG.

Beltrán, Joaquín, Laura Oso y Natalia Ribas (coord.) (2007). Empresariado étnico en España. CIDOB.

Bonacich, Edna (1973). A theory of middleman minorities. American Sociological Review, 38: 583-594. Doi: https://doi.org/10.2307/2094409. 
Cárdenas, Erika (2014). Migración interna e indígena en México: enfoques y perspectivas. Intersticios Sociales, 7, 1-28.

CDI (2020). Atlas de los Pueblos Indigenas de México. Recuperado de http://atlas.cdi. gob.mx.

Chávez, Amanda (2015). Sobre las transformaciones sociopolíticas (1970-2010) en las comunidades wixaritari de la Sierra Norte del Estado de Jalisco. (Tesis de doctorado en Ciencias Antropológicas). UAM

Chávez, María (2008). Las familias mazahuas de San Antonio Pueblo Nuevo, municipio de San José del Rincón, Estado de México, México. Agricultura, Sociedad y Desarrollo, 5(1), 71-91.

Contreras, José (2016). Los procesos migratorios de los indígenas en la Zona Metropolitana de Guadalajara: el caso de los huicholes o wixárikas: cultura y formas de vida. Punto CU Norte, 3, 151-175.

De la Peña, Guillermo (2006). Culturas indígenas de Jalisco. Secretaría de Cultura del Gobierno de Jalisco.

Díaz, Héctor (2009). La diversidad cultural y autonomía en México. Nostra ediciones.

Durin, Séverine (2003). Sur les routes de la fortune. Commerce a longue distance, endettement et solidarité chez les Wixaritari (Huichol), Mexique. (Tesis de doctorado). Universite Paris III.

Durin, Séverine y Alejandra Aguilar (2008). Regios en búsqueda de raíces y Wixaritari eculturísticos. En D. Séverine (coord...), Entre luces y sombras. Miradas sobre los indigenas en el área metropolitana de Monterrey (pp. 255-297). Monterrey: CIESAS/CDI.

Durin, Séverine y Nicolás Pernet (2010). Redes sociales. Etnicidad y recomposición de espacios residenciales en familias mazahuas de Temascalcingo en Monterrey. En L. Palacios (ed.) Cuando México enfrenta la globalización. Permanencias y cambios en el Área Metropolitana de Monterrey (pp. 174-196). Tijuana: El Colegio de la Frontera Norte.

Florentine, María y Alberto Romandía (2009). Emigración y continuidad cultural de los wixaritari. Breve reflexión sobre una relación ambigua. LiminaR, 7(2), 13-29. Doi: https://doi.org/10.29043/liminar.v7i2.296.

Flores, Alma y Javier Pérez (2017). Vendedores de fruta preparada. Indígenas nahuas en la Zona Metropolitana de Guadalajara. En P. Arias (coord.), Migrantes exitosos. La franquicia social como modelo de negocios (pp. 174-196). México: UdeG.

Flores, Alma, María Salinas y Ana Alejandre (2017). Muebleros de Capacuaro en la Zona Metropolitana de Guadalajara. En P. Arias (coord.), Migrantes exitosos. La franquicia social como modelo de negocios (pp. 197-213). México: UdeG. 
García de Wiegand, Acelia (2016). Chaquira de los indigenas huicholes: técnicas y diseños de 1820 a 1980. Secretaría de Cultura del Estado de Jalisco.

Gissi, Nicolás (2020). Etnografía de los Oaxaqueños en Ciudad de México. Relaciones interétnicas e inserción económica. Polis. Revista Latinoamericana, 57, 211-230.

González, Felipe (2017). Buscando un lugar en la economía: Modalidades de comercio practicadas por los mazahuas. Iztapalapa Revista de Ciencias Sociales y Humanidades, 38(83): 187-217. Doi: https://doi.org/10.28928/revistaiztapalapa/832017/ aot3/gonzalezortizf.

Granados, José y María Quezada (2018). Tendencias de la migración interna de la población indígena en México, 1990-2015. Estudios Demográficos y Urbanos, 33(2), 327-363. Doi: https://doi.org/10.24201/edu.v33i2.1726.

Güell, Berta, Sonia Parella y Hugo Valenzuela (2015). La economía étnica en perspectiva: del anclaje a la fluidez en la urbe global. Alteridades, 30: 37-50.

Gutiérrez del Ángel, Arturo (2002). La peregrinación a Wirikuta. El gran rito de paso de los huicholes. UdeG.

Herranz, Yolanda (2007). La formación del empresariado inmigrante en el contexto español. En J. Beltrán, L. Oso, y N. Ribas (coord.). Empresariado étnico en España (pp. 41-68). Barcelona: CIDOB.

Kloosterman, Robert, Joanne Van der Leun y Jan Rath (1999). Mixed-embeddedness: (In) formal economic activities and inmigrant businesses in the Netherlands. International Journal of Urban Research, 23(2): 252-266. Doi: https://doi. org/10.1111/1468-2427.00194.

Le Mûr, Rozenn (2015). La evolución del arte huichol junto al turismo. Entre apreciación y apropiación cultura. Desacatos, 49, 114-129.

Le Mûr, Rozenn (2018). Las estrategias discursivas de los artesanos huicholes en el marco turístico. Alteridades, 28(56), 97-108. Doi: https://doi.org/10.24275/uam/ $\mathrm{izt} / \mathrm{dcsh} /$ alteridades/2018v28n56/Le.

Liffman, Paul (2017). El agua de nuestros hermanos mayores. La cosmopolítica antiminera de los wixaritari y sus aliados. En O. Guilhem y J. Neurath (eds.) Mostrar y ocultar en el arte y los rituales: perspectivas comparativas (pp. 563-588). México: UNAM.

Light, Ivan (2007). Economías étnicas. En J. Beltrán, L. Oso y N. Ribas (coord.), Empresariado étnico en España (pp. 69-99). Barcelona: CIDOB.

Neurath, Johannes (2001). Lluvia en el desierto: el culto a los ancestros, los ritos agrícolas y la dinámica étnica de los huicholes $\mathrm{t}+$ apuritari. En J. Broda y J. Félix (coord.), Cosmovisión, ritual e identidad de los pueblos indígenas de México (pp. 485-526). México: CONACULTA/FONCA. 
Neurath, Johannes (2003). Huicholes. Colección Pueblos Indígenas del México Contemporáneo. CDI/PNUD.

Neurath, Johannes (2009). Reflexividad ritual y visiones múltiples en un cuadro de José Benítez Sánchez. Indiana, 26, 29-45.

Neurath, Johannes (2013). La vida en las imágenes. Arte huichol. México: Artes de México/CONACULTA.

Nolasco, Margarita (1987). Los indios de México. En S. Glantz (coord.), La heterodoxia recuperada. En torno a Ángel Palerm (pp. 347-367). México: FONCA.

Oehmichen, Cristina (2002). Comunidad y cosmovisión entre los mazahuas radicados en la Ciudad de México. Estudios de la Cultura Otopame, 3, 123-148.

Oehmichen, Cristina (2015). Identidad, género y relaciones interétnicas. Mazahuas en la Ciudad de México. UNAM.

Peraza, Brianda y Juan Mendoza (2015). Economía étnica mexicana: ¿factor de movilidad social y mejoramiento económico para sus trabajadores?. Ciencia UAT, 10(1): 32-46. Doi: https://doi.org/10.29059/cienciauat.v10i1.554.

Peraza, Brianda y Blas Valenzuela (2018). Economía étnica mexicana: Los Ángeles, California. Problemas del Desarrollo, 192(49): 85-107. Doi: https://doi.org/10.22201/ iiec.20078951e.2018.192.58714.

Portes, Alejandro y Robert Manning (1985). L'enclave ethnique: réflexions théoriques et études de cas. International Review of Community Development/ Reveu Internationale d'Action Communautaire, 14: 45-61. Doi: https://doi. org/10.7202/1034508ar.

Portes, Alejandro y Min Zhou (1996). Self-Employment and the Earnings of Inmigrants. American Sociological Review, 61(2):219-230. Doi: https://doi. org/10.2307/2096332.

Rubio, Miguel, Javier Gutiérrez, Carolina Sánchez, Alberto Valencia, Ángel Hernández, Rubén Araujo, Juan Atilano, Alejandro Balcazar, Verónica Villa, Fabiola Castillo y Leonor Tesso (200o). Desarrollo, marginalidad y migración. En INI/PNUD (ed.), Estado del desarrollo económico y social de los pueblos indígenas de México. Primer informe, Tomo 1, (pp. 289-354). México: INI/PNUD.

Tienda, Marta y Rebeca Raijman (200o). Immigrants'income packaging and invisible labor forcé activity. Social Science Quarterly, 81(1), 291-310.

Wiegand, Phil (2004). Sensacionalismo y etnografía: el caso de los huicholes de Jalisco. Relaciones. Estudios de Historia y Sociedad, 25(98), 49-68. 


\section{Sobre el autor}

Jorge Alberto Rodríguez Herrera es Licenciado en Desarrollo Regional por la Universidad de Guanajuato, Maestro en Desarrollo Local y Territorio por la Universidad de Guadalajara y Doctor en Ciencias Sociales por el Colegio de Michoacán, A.C. Investigador posdoctoral CONACyT en la Universidad de Guadalajara, México y miembro del Sistema Nacional de Investigadores en el nivel candidato. Ha desarrollado investigaciones sobre la multiactividad laboral de las familias en los ámbitos rural y urbano, abordando en este último espacio las distintas maneras en que los miembros de familias indígenas se insertan laboralmente en las ciudades mexicanas. Correo Electrónico: anjor2002@gmail.com. iD https://orcid.org/0000-0003-3767-030X 


\title{
CUHSO
}

Fundada en 1984, la revista CUHSO es una de las publicaciones periódicas más antiguas en ciencias sociales y humanidades del sur de Chile. Con una periodicidad semestral, recibe todo el año trabajos inéditos de las distintas disciplinas de las ciencias sociales y las humanidades especializadas en el estudio y comprensión de la diversidad sociocultural, especialmente de las sociedades latinoamericanas y sus tensiones producto de la herencia colonial, la modernidad y la globalización. En este sentido, la revista valora tanto el rigor como la pluralidad teórica, epistemológica y metodológica de los trabajos.

\author{
EDITOR \\ Matthias Gloël \\ COORDINADORA EDITORIAL \\ Claudia Campos Letelier \\ CORRECTOR DE ESTILO Y DISEÑADOR \\ Ediciones Silsag \\ TRADUCTOR, CORRECTOR LENGUA INGLESA \\ Aurora Sambolin Santiago \\ SITIO WEB \\ cuhso.uct.cl \\ E-MAIL \\ cuhso@uct.cl \\ LICENCIA DE ESTE ARTÍCULO \\ Creative Commons Atribución Compartir Igual 4.0 Internacional
}

